\title{
Schwannoma del nervio facial como diagnóstico diferencial en tumores de la región parotídea en pediatría
} Facial nerve schwannoma as differential diagnosis of parotid tumors in pediatrics

\author{
Dra. Carla Coraglia ${ }^{a}$ Dra. Julia Udaquiola ${ }^{a}$, Dr. Pablo Lobos ${ }^{a}$, Dr. Juan M. Moldes Larribas ${ }^{a}$ y Dr. Daniel H. Liberto
}

\section{RESUMEN}

El schwannoma es un tumor benigno originado de las células de Schwann y puede producirse a lo largo de cualquier nervio en el que estas células formen parte de su vaina. Los schwannomas del nervio facial extratemporales son infrecuentes y se presentan como masas indoloras en la región parotídea, de lento crecimiento y con compromiso del nervio facial. Se los debe tener en cuenta como diagnóstico diferencial en masas parotídeas en los niños, aunque sean raros. La utilización de la punción aspirativa con aguja fina y la resonancia magnética nuclear evidencia la mejor aproximación diagnóstica. El tratamiento quirúrgico de elección en la localización intraparotídea es la parotidectomía superficial. Otra opción es la tumorectomía completa con electroestimulación intraoperatoria y preservación del nervio facial. Se presenta un caso de schwannoma intraparotídeo en una paciente pediátrica operada con esta última técnica.

Palabras clave: schwannoma, neoplasias, glándula parótida, pediatría, nervio facial.

\begin{abstract}
Schwannomas are benign tumors which arise from Schwann cells and take place along peripheral nerves. Extra-temporal facial nerve schwannomas are infrequent and present as painless masses in the parotid region, slow-growing and involvement of the facial nerve. Although rare, they should be taken into account as a differential diagnosis in parotid masses in children. Surgical strategies include superficial parotidectomy and surgical tumor resection with electrical nerve stimulation and nerve preservation. The following case describes a paediatric patient treated with the previously mentioned nerve sparing surgical technique.
\end{abstract}

Key words: schwannoma, neoplasms, parotid gland, paediatrics, facial nerve.

http:/ / dx.doi.org/10.5546/ aap.2019.e301

Cómo citar: Coraglia C, Udaquiola J, Lobos P, Moldes Larribas JM, Liberto DH. Schwannoma del nervio facial como diagnóstico diferencial en tumores de la región parotídea en pediatría. Arch Argent Pediatr 2019;117(3):e301-e304.

a. Servicio de Cirugía y Urología Pediátrica, Hospital Italiano de Buenos Aires.

Correspondencia:

Dra. Carla Coraglia: carla.coraglia@hospitalitaliano.org.ar

Financiamiento: Ninguno.

Conflicto de intereses: Ninguno que declarar.

Recibido: 22-8-2018

Aceptado: 12-12-2018

\section{INTRODUCCIÓN}

El schwannoma (neurilemoma) es un tumor benigno que surge de las células de Schwann. Puede producirse a lo largo de cualquier nervio craneal o espinal en el que estas células formen parte de su vaina. Los schwannomas del nervio facial son infrecuentes; la mayoría son originados de su región intratemporal. Solo el $9 \%$ de los casos derivan de la porción intraparotídea del nervio, lo que representa del 0,2\% al 1,5\% de todos los tumores de la región parotídea. ${ }^{1}$ La mayoría de estos tumores en pediatría son benignos; los más frecuentes son los que se originan en la glándula, como los adenomas pleomorfos y las anomalías vasculares. ${ }^{2}$ Los tumores que se originan del tejido nervioso, como los schwannomas, son aún más raros, pero deben incluirse entre los diagnósticos diferenciales. ${ }^{2}$ Se presentan como masas sólidas, indoloras y de lento crecimiento, con diferente grado de afectación del nervio facial. Dada la escasa sintomatología con la cual aparecen, es difícil pensar en ellos como diagnóstico. ${ }^{3}$ Se reporta un caso clínico en una paciente pediátrica con diagnóstico de schwannoma intraparotídeo.

\section{CASO CLÍNICO}

Paciente de 16 años de edad, de sexo femenino, que consultó por presentar una tumoración en la región parotídea derecha, indolora, de 4 años de evolución. No refería síntomas acompañantes. Al momento del examen físico, se constató una lesión duro-elástica, polilobulada, con la piel de coloración normal, sin aumento de la temperatura local ni compromiso del nervio facial.

Se realizó una ecografía, que informó una formación sólida heterogénea de 35 × 24 mm en la región parotídea superior derecha. Para complementar el plan de estudio y descartar el compromiso de estructuras profundas, se realizó una resonancia magnética nuclear (RMN), que mostró una formación heterogénea de $30,5 \times 28 \times 36 \mathrm{~mm}$ (Figura 1). Como parte del algoritmo diagnóstico, se realizó una punción aspirativa con aguja fina (PAAF), que informó una proliferación fusocelular benigna vinculable 
con schwannoma. La inmunohistoquímica fue S100 positivo. Con estos hallazgos, se decidió la conducta quirúrgica. Se realizó una exéresis completa de la lesión, con electroestimulación intraoperatoria para identificar y evaluar la funcionalidad del nervio (Figura 3). La anatomía patológica confirmó el diagnóstico (Figura 2).

Para observar el compromiso del nervio facial, se utilizó la Escala de Gradación de la Función Muscular Facial de House-Brackmann en la evaluación pre- y posoperatoria, que resultó normal en todos los territorios (HouseBrackmann I).

Presentó buena evolución posoperatoria sin intercurrencias. En el seguimiento a largo plazo a 5 años, no se constató recidiva, con conservación completa de la función nerviosa y buena apariencia estética.

\section{DISCUSIÓN}

Los schwannomas son tumores benignos que surgen de las células de Schwann de cualquier vaina nerviosa, ya sea periférica o craneal. Los del nervio facial pueden surgir de cualquier parte del nervio en todo su trayecto intra- o extratemporal, desde la unión con la célula glialschwann al ángulo pontocerebeloso hasta sus ramas periféricas en la cara. Rara vez, surgen de la porción intraparotídea del nervio facial, ${ }^{3}$ como en el caso de nuestra paciente. Clásicamente, se presentan como masas parotídeas sólidas, móviles, de larga evolución, asintomáticas, con debilidad facial progresiva o parálisis facial periférica, debido a la compresión nerviosa por el crecimiento tumoral. ${ }^{4}$ Cuando el dolor o la parálisis facial no se resuelven, hay que sospechar malignidad.

FIGURA 1. Resonancia magnética nuclear: ponderación T2, cortes coronal (A), axial (B) y parasagital (C). Se observa una lesión hiperintensa, heterogénea de 30,5 ×28 × $36 \mathrm{~mm}$ en la región parotídea

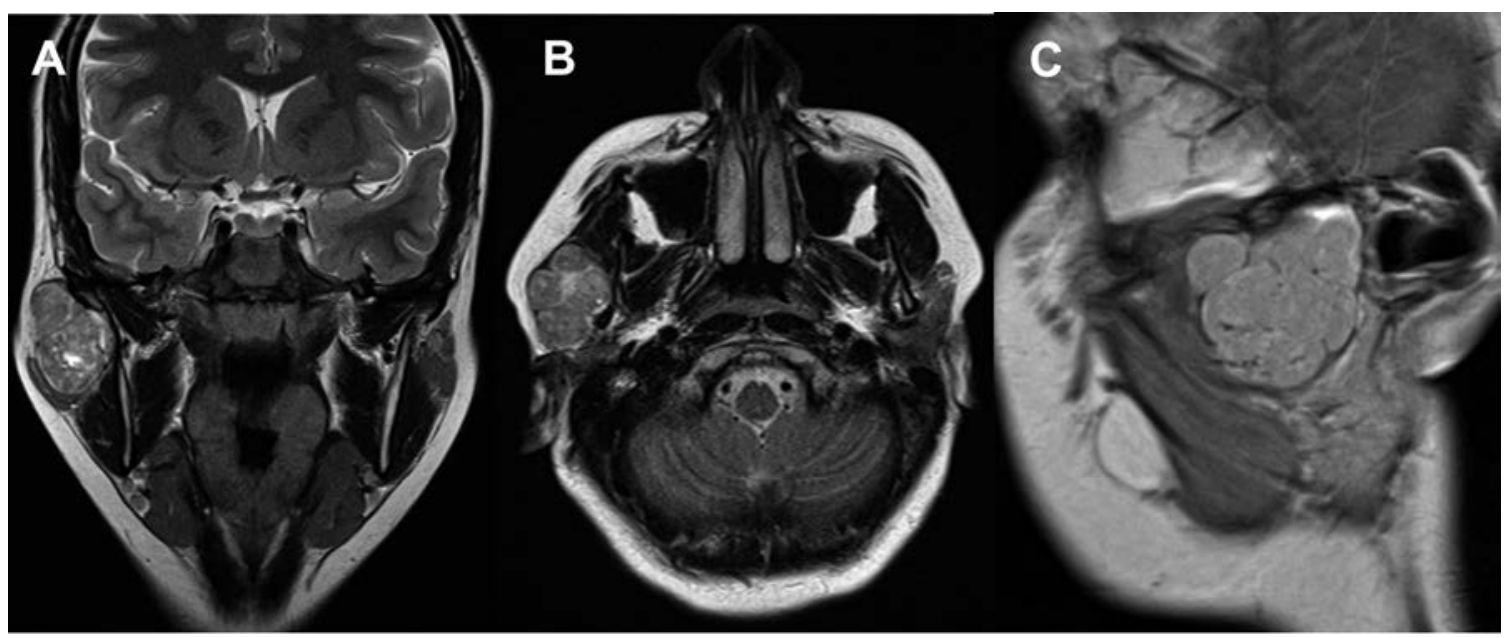

FIGURA 2. Anatomía patológica de la punción aspirativa con aguja fina guiada por ecografía. Tinción HyE. Se observa una proliferación fusocelular benigna vinculable con schwannoma, a. 10x, b. $20 x$

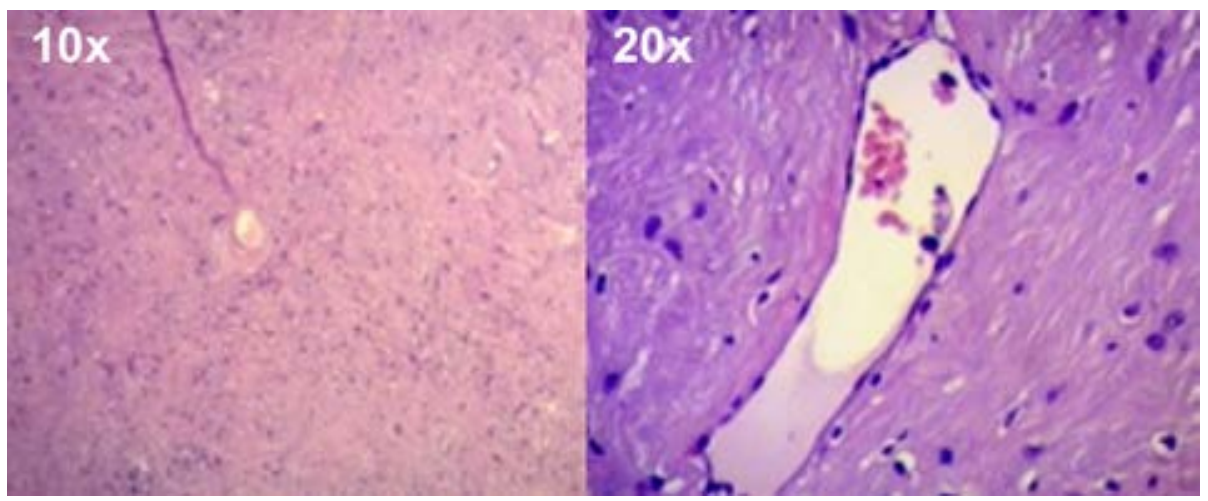


Son tumores raros en la población pediátrica; el primer reporte de la literatura inglesa es del año 1996 por Kumar y colaboradores. ${ }^{3}$

El diagnóstico preoperatorio es fundamental para la planificación quirúrgica, pero es difícil, debido a la baja frecuencia que presenta y los pocos signos típicos asociados. ${ }^{5}$ No hay imágenes patognomónicas de este tipo de tumores. En la ecografía, se presentan como masas hipoecogénicas con forma de huso y áreas quísticas, pero su utilidad es limitada, ya que no permite localizar con certeza la ubicación del nervio facial y su compromiso. En la tomografía computada, se muestran como masas de superficie lisa, bien delimitadas, y permite, además, evaluar si existe compromiso óseo. ${ }^{5}$

En la actualidad, el método no invasivo por excelencia para la evaluación preoperatoria es la RMN. ${ }^{1,5}$ Brinda información sobre la localización del tumor dentro del recorrido del nervio, la profundidad y la afectación de la glándula parótida. Además, ayuda a orientar sobre el origen neurogénico de la lesión, debido a que se presentan, característicamente, como tumores bien definidos originados de la vaina nerviosa del nervio, que son isointensos en $\mathrm{T} 1$, con aumento de la intensidad en la periferia y disminución de la intensidad central en T2 (signo diana). ${ }^{1}$ Este método permite también determinar la extensión de la resección que será necesario llevar a cabo. La RMN fue el método elegido para evaluar la lesión en nuestra paciente.

Se puede realizar una PAAF de la lesión para obtener la muestra citológica y lograr el diagnóstico definitivo; sin embargo, esto es posible solo en el $17,6 \%$ de los casos, ${ }^{5}$ debido a que, si el schwannoma tiene áreas de degeneración quística o mixoide, o una alta proporción de colágeno, la punción puede ser no diagnóstica e, incluso, algunas veces, tener un resultado preoperatorio erróneo. ${ }^{1,6}$ En nuestro caso, la PAAF nos permitió arribar al diagnóstico. Histológicamente, se presentan como una lesión sólida, bien delimitada y encapsulada que no invade el tejido circundante. Dentro de la masa, se observa una arquitectura bifásica conformada con áreas hipocelulares con abundante material acelular y otras áreas hipercelulares con abundantes núcleos y citoplasma. ${ }^{6}$

Las tinciones inmunohistoquímicas pueden ayudar al diagnóstico diferencial. Los marcadores más usados son el S100, actina del músculo liso, CD68, pancitoqueratina y calretinina. Estos tumores son muy positivos para la tinción S100, que es el más específico para su diagnóstico. ${ }^{6} \mathrm{La}$ actina del músculo liso sirve para diferenciarlos de aquellos tumores de origen muscular. El CD68 puede ser utilizado para descartar una lesión histiocítica. La pancitoqueratina lo diferencia de los tumores de origen epitelial. La calretinina es útil para distinguir el schwannoma del neurofibroma, dado que el primero mostrará una tinción difusa, mientras que el segundo se teñirá débilmente o no lo hará. ${ }^{6}$

Para evaluar de manera objetiva la función del nervio facial tanto pre- como posoperatorio, se puede utilizar la Escala de Gradación de la Función Facial de House-Brackmann (Figura 4), que establece seis categorías o grados de disfunción, que van desde grado I o función normal de todos los territorios nerviosos hasta grado grado VI con parálisis total y pérdida del tono.,

Figura 3. A. Aspecto preoperatorio. B y C. Exéresis tumoral. Se observa la glándula parótida indemne por debajo del tumor $\left({ }^{*}\right)$. D. Pieza quirúrgica

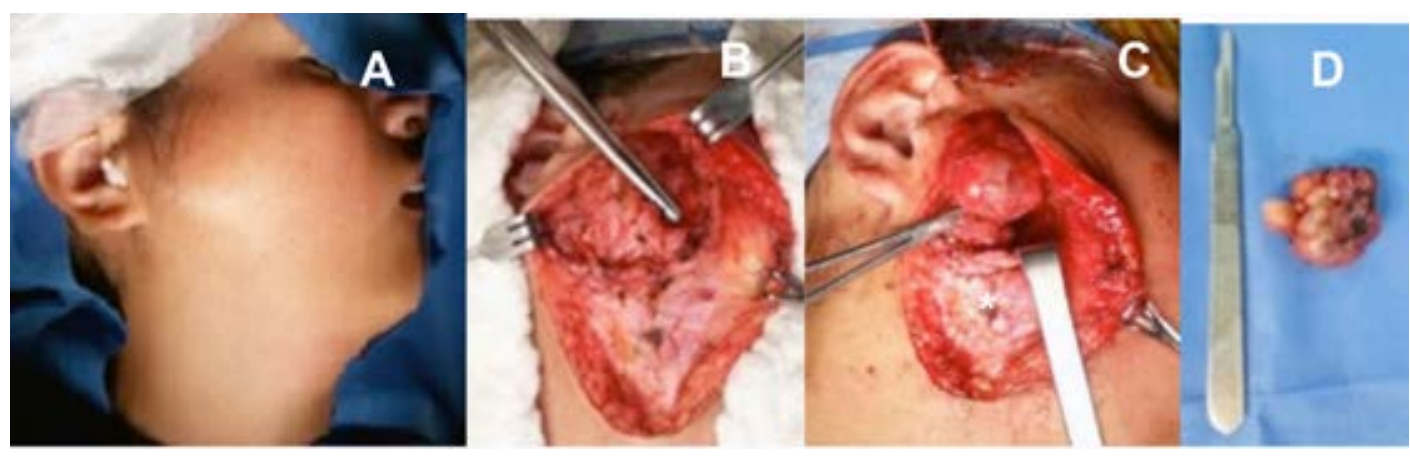


La decisión final de resecar un schwannoma del nervio facial sigue siendo controvertida, en parte, debido al crecimiento benigno y lento del tumor versus el riesgo de posibilidad de lesión nerviosa permanente durante la resección. Algunos autores prefieren la resección en casi todos los casos, mientras que otros han demostrado que la descompresión del nervio facial o incluso solo la observación pueden ser alternativas útiles. ${ }^{9}$

Si el nervio facial está gravemente afectado (House-Brackmann V o VI), entonces, la elección es la extirpación del tumor y el injerto nervioso si es factible. Con la función del nervio facial conservada, se puede optar por la resección, la descompresión o la observación con un seguimiento con electroneurografía e imágenes. ${ }^{1,4-9}$

En la localización intraparotídea, la parotidectomía superficial es la técnica de elección. Durante esta, la disección tumoral suele ser difícil, lo que aumenta el riesgo de sección del nervio facial. Esto se puede evitar mediante la localización del nervio con estimulación eléctrica. La electroestimulación del tumor es un método muy característico que da como resultado el movimiento de los músculos faciales afectados. ${ }^{9}$ La dificultad intraoperatoria para localizar el nervio facial durante la extirpación del tumor es una característica diagnóstica del schwannoma del nervio facial intraparotídeo. ${ }^{10}$ Debe considerarse, según la experiencia del equipo tratante, la tumorectomía completa con preservación del nervio.

En nuestro caso, la correcta identificación del nervio facial antes de iniciar la exéresis tumoral, asociada al uso de la técnica de electroestimulación intraoperatoria, permitió evitar su sección y disminuir la morbilidad de la paciente. Las recidivas son inusuales luego de la extirpación quirúrgica y el pronóstico es excelente. ${ }^{9,10}$

En conclusión, toda masa parotídea en los niños debe ser investigada antes de planificar un tratamiento quirúrgico. La utilización de la RMN y la PAAF ayuda a la mejor aproximación diagnóstica. Debido a la rareza de los schwannomas, para la toma de decisiones quirúrgicas, se sugiere guiarse por la experiencia del equipo y considerar la Escala de House-Brackmann para evaluar el compromiso nervioso.

Figura 4. Escala de Gradación de la Función Muscular Facial de House-Brackmann ${ }^{8}$

\begin{tabular}{ll}
\hline Grado I & Función normal en todos los territorios. \\
\hline Grado II & $\begin{array}{l}\text { Disfunción leve. Ligera o leve debilidad de la musculatura, apreciable tan solo ante la inspección meticulosa. En } \\
\text { reposo, simetría normal. Sin sincinesias ni contracturas ni espasmos faciales. }\end{array}$ \\
\hline Grado III & $\begin{array}{l}\text { Disfunción moderada. Diferencia clara entre ambos lados sin ser desfigurante. Incompetencia para el cierre } \\
\text { palpebral completo; hay movimiento de la región frontal, asimetría de la comisura bucal en movimientos } \\
\text { máximos. En reposos, simetría y tono normal. }\end{array}$ \\
\hline Grado IV & $\begin{array}{l}\text { Disfunción moderada-grave. Debilidad o asimetría desfiguradora. En reposo, simetría y tono normal. No hay } \\
\text { movimiento de la región frontal; imposibilidad de cerrar el ojo totalmente. Sincinesias. Espasmo facial. }\end{array}$ \\
\hline Grado V & Disfunción grave. Tan solo ligera actividad motora perceptible. En reposo, asimetría. \\
\hline
\end{tabular}

\section{REFERENCIAS}

1. Shimizu K, Iwai H, Ikeda K, Sakaida N, et al. Intraparotid Facial Nerve Schwannoma: A Report of Five Cases and an Analysis of MR Imaging Results. AJNR Am J Neuroradiol. 2005; 26(6):1328-30.

2. Osterreich R, UdaquiolaJ,Lobos P,Moldes J, etal.Diagnóstico y tratamiento de los tumores de la región parótida en pediatrica: cohorte. Cir Pediatr. 2016; 29(4):135-41.

3. Kumar B, Wash M, Walter N, Path N, et al. Intraparotid facial nerve schwannoma in a child. J Laryngol Otol. 1996; 110(12):1169-70.

4. Cauchey R, May M, Schaitkin B. Intraparotid facial nerve schwannoma: Diagnosis and management. Otolaryngol Head Neck Surg. 2004; 130(5):586-92.
5. Lobos A, Cardemil F, Villagrán D. Schwannoma del nervio facial como diagnóstico diferencial de tumor parotídeo. Reporte de un caso. Rev Chil Cir. 2009; 61(6):556-9.

6. McCarthy WA, Cox BL. Intraparotid Schwannoma. Arch Pathol Lab Med. 2014; 138(7):982-5.

7. House JW, Brackmann DE. Facial nerve grading system. Otolaryngol Head Neck Surg. 1985; 93(2):146-7.

8. Marchioni D, Alicandri Ciufelli M, Presutti L. Intraparotid facial nerve schwannoma: literature review and classification proposal. J Laryngol Otol. 2007; 121(8):707-12.

9. Kisil Y, Yilmaz M, Aydil U, Ermen O, et al. Facial schwannoma of the parotid gland in a child. Kulak Burun Bogaz Ihtis Derg. 2008; 18(3):175-8.

10. Sneige N, Batsakis J. Primary tumors of the facial (extracranial) nerve. Ann Otol Rhinol Laryngol. 1991; 100(7):604-6. 